\title{
Retraction Note to: Bibliometric study of Electronic Commerce Research in Information Systems \& MIS Journals
}

\author{
Arthur Jing Lin $^{1}$. Chien-Lung Hsu ${ }^{2}$. Chun-Hao Chiang ${ }^{3}$ \\ Published online: 17 December 2020 \\ (c) Akadémiai Kiadó, Budapest, Hungary 2020
}

\section{Retraction Note to: Scientometrics (2016) 109:1455-1476 https://doi.org/10.1007/s11192-016-2142-8}

\begin{abstract}
Akadémiai Kiadó and Springer Nature are retracting this article (Lin et al. 2016) because the pattern of overlap with other published articles (Rorissa and Yuan 2012; Hsu et al. 2015) calls the validity of the data into question. In addition, there are concerns with respect to the reliability of the data presented. None of the authors have responded to correspondence from the Publisher about this retraction.
\end{abstract}

\section{References}

Hsu, C-L, Westland, JC, Chiang C-H (2015) Editorial: Electronic Commerce Research in seven maps. Electronic Commerce Research, (2015) 15: 147

Lin, A.J., Hsu, CL. \& Chiang, CH. Bibliometric study of Electronic Commerce Research in Information Systems \& MIS Journals. Scientometrics 109, 1455 -1476 (2016). https://doi.org/10.1007/s1119 2-016-2142-8

Rorissa, A., \& Yuan, X.J. (2012). Visualizing and mapping the intellectual structure of information retrieval. Information Processing \& Management, 48(1), 120-135

The original article can be found online at https://doi.org/10.1007/s11192-016-2142-8.

Chien-Lung Hsu

alanhsu8399@takming.edu.tw

Arthur Jing Lin

arthurhagnes@gmail.com

Chun-Hao Chiang

hector@megaholdings.com.tw

1 Graduate Institute of International Business, National Taipei University, San Shia Campus: 151, University Rd., San Shia District, New Taipei City 23741, Taiwan, ROC

2 Department of Marketing Management, Takming University of Science and Technology, No. 56, Sec. 1, Huanshan Rd., Neihu, Taipei City 11451, Taiwan, ROC

3 Department of Risk Control Management, Mega Financial Holding Company, 14F, No. 123, Sect. 2, Jhongsiao E. Road, Taipei 100, Taiwan, ROC 